\title{
Research on The Impact of Childhood Coping Strategies in Academics and Adolescence Lives of Students using Data Mining
}

\author{
S. Vallikala, V. Geetha., V. Jalaja Jayalakshmi
}

\begin{abstract}
The role of a counsellor in educational institutions revolves mostly around academic and behavioural issues. The aim of this study is to identify common sources of stress among adolescence students and to determine the impact of coping strategies practised by the students in academics and life in general. The association between adolescent life, geographical location, stress sources, and coping strategies is explored in this work. Diverse factors contribute to stress, agitation and academic performanceamong students. The major factors that were considered for this study are regional and familial backgrounds of the students, their gender, residential status, communication skills, the five childhood coping strategies and their influence in the campus life. Counselling sessions were conducted for the students and the empirical data is classified using data mining techniques to analyze the factors that contribute to the behavioural aspects of the students.

Keywords - Academic, Behavioural, Adolescent, Coping strategies, Counselling, Data Mining
\end{abstract}

\section{INTRODUCTION}

Academic pressure is one of the main causes of stress for adolescents and stress is a significant catalyst and precursor to depression. Coping has been viewed as a behavioural manifestation that may assist an individual in psychosocial adaptation during stressful events of life. This research uses to sensitize the academicians in understanding the related concerns of stress in students thereby proceeding to provide personal assistance and care to enhance their academic performance, career choices and emotional well-being [1]. Current study was aimed to find out prevalence of educational stress among adolescents and the impact of associated factors.

Data mining can be used to discover patterns occurring in the databases such as associations, classification models, clustering, sequential patterns etc. Data classification is one of the most important data mining techniques which play an important role in organizing the data. Classification assigns items in a collection to target categories or classes and the goal of classification is the accurate prediction of target class for each class of data (Aggrawal and Yu 1999).

Data mining techniques have been widely used to analyze the behavioural patterns of the students. A web application was developed for guiding high school students to choose

Revised Manuscript Received on July 18, 2019.

S. Vallikala, Student Counsellor, Kumaraguru College of Technology, Coimbatore, India.(E-mail:.vallikala.counselor@kct.ac.in)

V. Geetha, Professor, Dept. of Computer Applications, Kumaraguru College of Technology, Coimbatore, India.(Email:.geetha.v.mca@kct.ac.in)

V. Jalaja Jayalakshmi, Assistant Professor,Dept. of Computer Applications, Kumaraguru College of Technology, Coimbatore, India.(Email:.jalajajayalakshmi.v.mca@kct.ac.in) their career based on personality trait, interest and student capacity. The results were analysed using decision tree and ADA Boost data mining techniques [2]. Classification techniques are used in educational databases to recommend career options for high school students and also to predict the possible violent behaviour among the students [3].

The aim of this study is to identify reasons of stress among adolescent [4] students and to determine the impact of coping strategies [5] in academics and their life by considering the various factors. Counselling sessions were conducted for the needed students and the empirical data is collected. Data mining techniques are used to classify the coping strategies of the students and analyze the factors that contribute to behavioural aspects.

\section{PSYCHOLOGICAL DIMENSIONS}

The various psychological dimensions related to the behavioural pattern of adolescentsare discussed in this section.

\section{A. Coping Strategies}

Coping strategies which has been followed from the childhood of a person is the most familiar and repetitive pattern in all stages of life. This study focuses on the impact of five coping strategies such as Procrastination, Agitation, Avoidance, Adaptation, and Apprehension.

\section{B.Procrastination}

Procrastination is an active process wherein the individual chooses to do something else instead of the task that is focussed to put off or delay when immediate attention is required. It almost always adds stress, disorganization, and discomfort. Students are doubtful, self critical and with low self esteem when they are unable to match with the pace of the academics. Late submission of assignments, presentations, projects and incomplete lab manuals are the commonly observed behaviours among such students.To accomplish an outcome, a person needs to initiate the process. Students who are procrastinating think, imagine and tend to plan for a perfect structure. When they delay they become self critical and to hide the guilt, they unconsciously pretend to be busy with reasons to support the childhood strategy of procrastination [6]. When they are facilitated they choose to move on by sharing their plans to their faculty mentors. With the supervision and guidance when each step

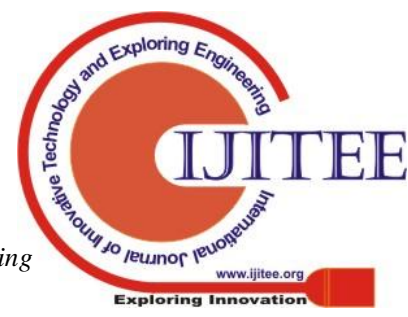




\section{RESEARCH ON THE IMPACT OF CHILDHOOD COPING STRATEGIES IN ACADEMICS AND ADOLESCENCE LIVES OF STUDENTS USING DATA MINING}

of the plan is accomplished within the time frame their confidence level progresses which in turn enhance their academic performance.

\section{Agitation}

If someone is in a state of agitation, they are very worried or upset it is observed in their behaviour, physical movements or voice.

Symptoms of agitation [7] include:

- extreme irritability, like snapping at friends and family, or being annoyed at small things

- anger

- fidgeting

- racing thoughts and incessant talking

- restlessness

- pacing

- hand-wringing, finger tapping

- nail-biting

- outbursts of complaining or shouting

- pulling clothes or hair

- picking at skin

Students tend to exhibit the above behavioural patterns which are visible and uncommon inside and outside the class. The faculty mentor picks up the clues and refers them for counselling sessions. The authentic feeling [8] behind the behaviour is processed to invite them to re-think and plan.

\section{Avoidance}

Avoidance [9] behaviour is when a person consciously or unconsciously escapes from an uncomfortable situation instead of dealing with. It is seen that people who experience anxiety, stress, or depression are more prone to this behaviour.

Absenteeism, not appearing for group presentations, project reviews and not submitting the assignments was the common behaviours exhibited by the students who follow this childhood strategy. They become aware and accept that they have grown up now and capable of facing the reality with new choices post counselling sessions.

\section{E.Adaptation}

Adaptation refers to an individual's ability to adjust to changes, new experiences, and to accept new information. The ability to adapt helps us grow mentally and continually develop. On the contrary, adaptation [10] may also be unwilling but forced by self to fit into the environment.

Students meekly follow the rules, develop a vague identity for themselves and continue to grow with the available resources. There is a general reluctance to explore, create new resources and progress. It is the level of confidence and self esteem which denotes the positivity or the need of facilitation by the counsellor.

Adaptive students who exhibit team spirit, leadership skills etc are honed to continue their pace of progress and who are comfortably settled down with mediocre goals are facilitated to take risks and progress. They identify their talents and outsmart themselves post counselling sessions..

\section{F Apprehension}

Anxious expectation, worry, general uneasiness, or dread about a situation, event and the fear of future and uncertainty is generally termed as apprehension [11].
Students contemplate and continue to wait for a magical solution without their contribution or risk taking mostly depending and allowing others to decide for them. They are fearful and self-doubtful in a new environment. The trust towards self, others and life is constantly in the contemplating mode. During challenging situations they isolate themselves, depend on a source from where they get solace. Unhealthy symbiotic dependency, conflicts, trust related issues, exam fear, panic attacks, psychosomatic illnesses are the common symptoms observed among such students.

During the sessions they take time to settle down and share their discomforts. When they initiate to process their vulnerabilities they move on with confidence. Counselling provides a safe space and relief for such students.

\section{METHODOLOGY}

This section discusses about the methods used for collecting the data needed for analysis.

Samples of students who have attended the counselling sessions and are in the process of positive change were chosen for the study. Students while attending the initial session were inhibitive and closed. After two to three adaptive follow up sessions, the rapport and trust was built following which, the student opens up to share and face the unexplored self to progress in academics and personal life. The coping strategies have been categorised under five major criterions: procrastinating, avoiding, agitating, apprehensive and adapting. These strategies were not helping when the situation was stressful in their adolescent life. At this juncture, the student taking guidance and facilitation from the counsellor is ideal.

Each student is given confidential and personal attention to explore the choices of growth and progress. The regional and cultural beliefs which add to the value system are reinforced and facilitated to be followed. The limiting and negatively influencing beliefs and behaviours are identified and facilitated to focus on other positive doable goals.

\section{A Classroom Observation}

Academic performance of a student is the indicator for the faculty to identify the student stress level. Low attendance percentage, failure in examinations and laboratory practical is an alert call for the academic mentor to pay special attention towards the particular student. Mentor observes the following behaviours of the students in the classroom.

1. What type of classroom activities they are interested?

2. How students interact with each other?

3. Who initiates the conversation/activities etc?

4. What is the nature of class cohesiveness observed?

5. Anyone left out/ chooses to stay aloof in the class?

6. Is peer support provided and whether it is for the progress of each other?

Student, who is aloof, suddenly isolates self from class activities; sleeps during class hours, quarrelsome, suspicious, and not included by the peers, exhibits disorganised way of presenting self are the behavioural manifestations that need help. These are evident clues to the

Published By: 
observer that the student needs immediate attention and care. Often the reasons behind such behavioural patterns [12] are emotional, personal, unaware childhood coping strategies. The attributes considered for this study is shown in TABLE I.

\section{III.2 Data Mining Methodology}

The childhood coping strategies that are challenging to handle in the campus life is processed through counselling sessions. Students explore other new options to face the current challenging situation. The commonality observed in the data which manifests the childhood coping strategy can be analysed using the data mining decision tree classification algorithm.

Decision trees are powerful tools for classification and prediction. It uses divide and conquer strategy to create a tree structure which represents the rules. It calculates the information gain for each attribute and then selects the attribute with the highest information gain. The tree was created using J48 algorithm in WEKA data mining tool and is depicted in Fig. 1. The rules corresponding to the generated decision tree are shown in Fig. 2.

\section{TABLE I.STUDENT ATTRIBUTES}

\begin{tabular}{|c|c|c|c|c|c|c|}
\hline Gender & Location & Stay & Position & Family & Bonding & Communication \\
\hline $\begin{array}{c}\text { Male/ } \\
\text { Female }\end{array}$ & $\begin{array}{c}\text { Rural/Urban /Semi } \\
\text { urban }\end{array}$ & $\begin{array}{c}\text { Hostel/ } \\
\text { Home }\end{array}$ & $\begin{array}{c}\text { Single child / } \\
\text { Siblings }\end{array}$ & $\begin{array}{c}\text { Nuclear/ } \\
\text { Joint }\end{array}$ & $\begin{array}{c}\text { Close knit } / \\
\text { Distant }\end{array}$ & Active/ Passive \\
\hline
\end{tabular}

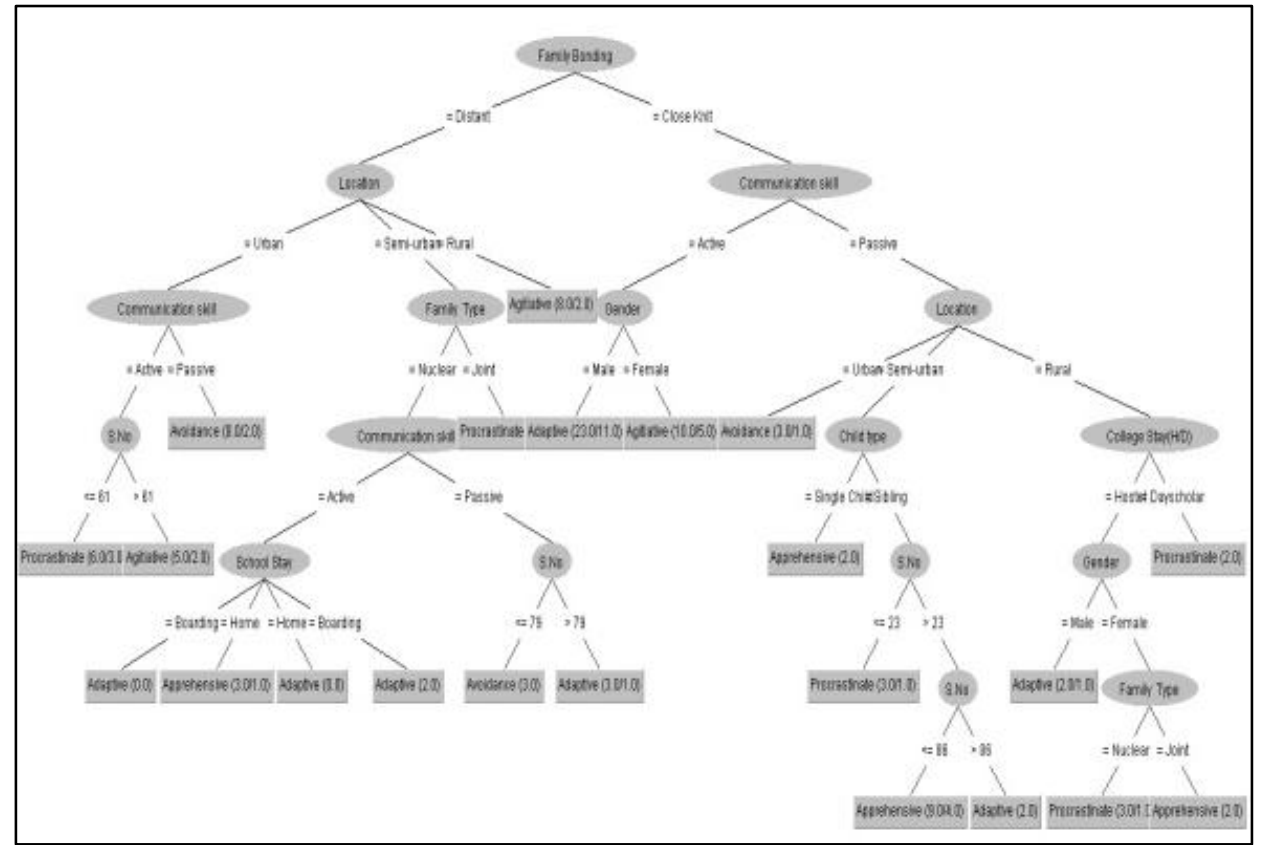

Fig. 1.Decision tree generated by J48 algorithm.

TABLE II. Summary of findings of Decision Tree algorithm

\begin{tabular}{|c|c|c|c|c|c|}
\hline \multirow{2}{*}{ Data } & \multicolumn{5}{|c|}{ Coping Strategies } \\
\hline & Procrastination & Agitation & Avoidance & Adaptation & Apprehension \\
\hline Gender & - & Female & - & Male & Female \\
\hline Location & Urban/ Semi urban & Rural/ Urban & Urban & Semi urban & Semi urban \\
\hline Stay & Day scholar & - & - & $\begin{array}{lll}\text { Day scholar } & / \\
\text { Hostel } & & \end{array}$ & Day scholar \\
\hline Position & Single child & Siblings & - & - & - \\
\hline Family type & Joint & - & - & Nuclear & Joint \\
\hline Family bonding & Distant/ Close knit & Distant/Close knit & $\begin{array}{ll}\text { Close } & \text { knit/ } \\
\text { Distant } & \end{array}$ & Distant/ Close knit & $\begin{array}{l}\text { Distant/ Close } \\
\text { knit }\end{array}$ \\
\hline Communication & Active/ Passive & Active & Passive & Active & Active \\
\hline
\end{tabular}

From the decision tree, it can be seen that the attribute Family Bonding has the maximum contribution with a high information gain on the coping strategies: Procrastination, Agitation, Avoidance, Adaptation and Apprehension.

\section{DISCUSSION \& RESULTS}

The observable behavioural patterns of the students classified using data mining techniques are described in this section. 


\section{RESEARCH ON THE IMPACT OF CHILDHOOD COPING STRATEGIES IN ACADEMICS AND ADOLESCENCE LIVES OF STUDENTS USING DATA MINING}

\section{A Procrastination}

Students from urban/semi urban locations, from a joint family setup and being single child tend to procrastinate. It is their childhood coping strategy. Family bonding (distant/close) and level of communication (active/passive) of such students are equally correlative to their procrastinating coping factors.

\section{$B$ Agitation}

Women students coming from rural/urban locations having siblings observe agitation as their childhood coping strategy. Family bonding (Distant/ Close knit) with active level of communication are equally correlative to their agitating coping factors.

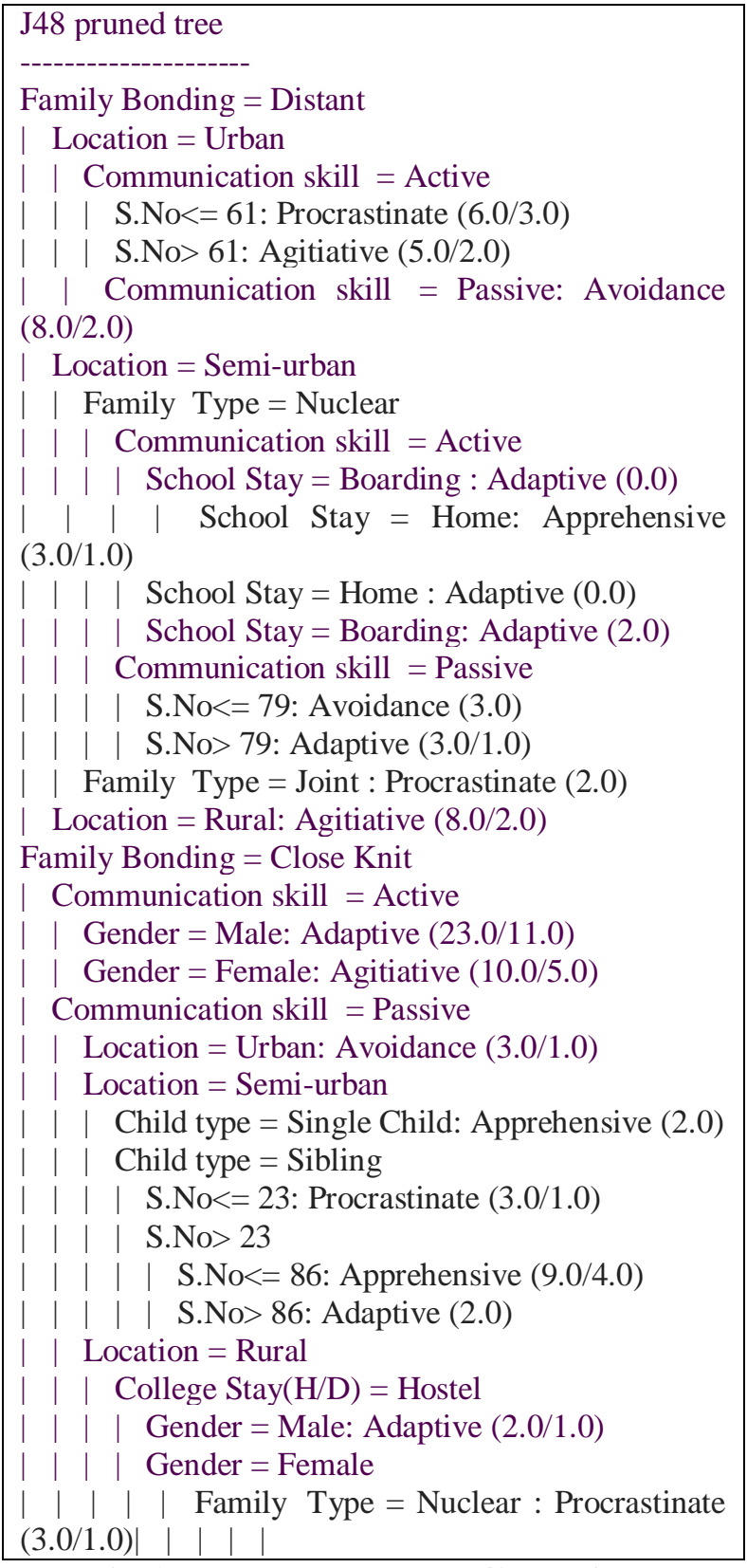

Fig. 2. Rules generated by J48 algorithm

\section{Avoidance}

Students hailing from urban location with passive communication skills follow avoidance as their childhood coping strategy. Family bonding (Distant/ Close knit) of these students are equally correlative to their avoiding coping factors.

\section{Adaptation}

Men students from semi-urban location having nuclear family background with active communication skills have adaptation as their childhood coping strategy. Family bonding (Distant/ Close knit) and residential status are equally correlative to theiradaptive coping factors.

\section{E Apprehension}

Women day scholar students from semi-urban location from a joint family type with active communication skills have apprehension as their childhood coping strategy. Family bonding (Distant/ Close knit) of these students is equally correlative to their Apprehensive coping factors.

The findings are summarized in TABLEII.

Factors contributing for the coping strategies

The various factors which relate to the coping strategies are discussed below:

\section{a) Communication}

Every student follows his/her specific method (active/ passive) of communication to connect with others. Their childhood experiences and the family background have a significant influence on their communication style as they grow. Active communicators are good listeners, influential in any conversation and capable of verbally persuading others, whilst passive communicators are good listeners and often avoid to voice out their views.

\section{b) Family}

Parental support and guidance plays a major role in the emotional wellbeing of the students. Working /single parents and parents who are facing conflicts, financial loss and business stress were lacking effective parenting skills. The distant /close knit family bonding, trust and intimacy between the child and the parent, the presence and absence of a sibling some of the powerful influencing factors in the students' college life. Students who have intimate family ties, with siblings were willing to share with peers and socialize.

\section{c) Stay}

Few students who were sent to boarding school at early childhood were experiencing separation anxiety. Some were adaptive and comfortable to take decisions, to share and make social contacts wherein few other students found it difficult to trust others. It is due to their exposure to an unfamiliar environment at an early age and the fear was yet to be addressed. Communication skills of introvert students were poor, often finding difficult to socialize, attachment and belongingness to a group or team is also a challenging factor for them.

\section{d) Location}

Geographical location influences the cultural beliefs and moral values of a child and reinforced by the family. 
The city, town or village from where the student belongs plays a significant role in the communication style, classroom behaviour, stress sources and coping strategies.

\section{CONCLUSION}

Adolescent student life is a turbulent and transforming journey. Often they experience standing at cross roads, stressful to decide and progress. This paper helps in identifying the major factors those impact the behavioural pattern of the students by using data mining techniques. Though each student is unique, this classification might help to predict the attributes that are contributing to their coping strategies.

Faculty mentoring, psychological counselling, timely referral, intervention and awareness about the childhood coping strategies facilitate and prepare the students towards academic progress and socializing skills that are important for their professional and personal growth.

\section{REFERENCES}

1. Vallikala, S,Vijilesh, V,Priyadarshini, R, "Establishing Counselling Services in Academic Institutions: An Experiential Sketch",International Journal of Pure and Applied Mathematics, Volume 119, No. 17, 2018, 22532261.

2. Nikita Gorad, IshaniZalte, Aishwarya, Nandi and DeepaliNayak, "Career Counselling using DataMining", International Journal of Innovative Research in Computer and Communication Engineering, Volume 5, Issue 4, April 2017.

3. Elakia, Gayathri, Aarthi, Naren J, "Application of Data Mining in Educational Database for Predicting Behavioural Patterns of the Students", (IJCSIT) International Journal of Computer Science and Information Technologies, Vol. 5 (3), 2014, 4649-4652.

4. Compas BE, Connor- Smith JK, Saltzman H, Thomsen AH, Wadsworth ME (2001),"Coping with stress during childhood and adolescence problems, progress, and potential in theory and research", Psychol Bull 127: 87127.

5. Ebata AT, Moos RH (1991),"Coping and adjustment in distressed and healthy adolescents", Appl Dev Psychol 12: $33-54$.

6. Seiffge - Krenke I (2013), "Stress, coping, and relationships in adolescence", Psychology Press.

7. Spirito, A., Stark, L.J., Grace, N., Stamoulis, D (1991), "Common problems in coping strategies reported in childhood and early adolescence". J. Youth Adolescence 20: 531-534.

8. WF Cornell, "Life script theory: A critical review from a developmental perspective", Transactional Analysis Journal,1988, Taylor\& Francis.

9. Zimmer- Gemback, MJ and Skinner, EA, (2011) "The development of coping across childhood and adolescence: An integrative review and critique of research", International Journal of Behavioral Development, 35(1), 117.

10. Fields, L and Prinz, RJ, "Coping and adjustment during childhood and adolescence", Clinical Psychology Review, Volume 17, Issue 8, December 1997, Pages 937-976.

11. Cummings, E. M., Greene, A. L., and Karraker, K. H. (1991). "Life-span developmental psychology: Perspectives on stress and coping", Hillsdale, NJ, US: Lawrence Erlbaum Associates, Inc.

12. Hargaden, H, Sills, C, (2002) "Transactional Analysis: A relational perspective", Brunner - Routledge, UK. 